\title{
Softwares Educacionais como Auxílio ao Processo de Alfabetização de Estudantes da Educação Infantil
}

\author{
Sivaldo Joaquim de Santana ${ }^{1}$, Wilk Oliveira dos Santos ${ }^{2}$ \\ ${ }^{1}$ Núcleo de Excelência em Tecnologias Sociais (NEES) - Instituto de Computação (IC) \\ Universidade Federal de Alagoas (UFAL) - CEP: 57.072-900 - Maceió, AL - Brasil. \\ ${ }^{2}$ Laboratório de Computação Aplicada à Educação e Tecnologia Social Avançada \\ (CAEd) - Instituto de Ciências Matemáticas e de Computação (ICMC) \\ Universidade de São Paulo (USP) - São Carlos, SP - Brasil. \\ sivaldojoaquimeic.ufal.br, wilk.oliveira@usp.br
}

\begin{abstract}
Resumo. Apesar do crescente uso de softwares educativos no ensino básico em geral, a utilização destes softwares de maneira positiva na educação infantil ainda é um desafio pertinente. Neste sentido, este artigo tem por objetivo relatar a experiência do uso de diferentes Tecnologias Digitais de Informação e Comunicação (TDIC) no processo de alfabetização de 67 estudantes com idade entre 4 e 5 anos, em uma escola de Educação Básica, localizada ao Sul do Estado de Alagoas, a fim de verificar o impacto destas tecnologias no processo de alfabetização dos estudantes. Para isso, foi utilizada uma abordagem qualitativa com ênfase na observação participante como técnica de coleta de dados. Como resultados, verificou-se que o uso das TDICs impactou positivamente no desempenho, contribuindo para aumentar o engajamento, motivação, atenção, colaboração e compartilhamento de estratégias de resolução de problemas por parte dos estudantes.
\end{abstract}

\begin{abstract}
Despite the increasing use of educational software in the basic education, the use of these software in a positive way in early childhood education is still a relevant challenge. In this sense, this paper aims to report the experience of the use of different Digital Information and Communication Technologies (DICT) in the literacy process of 67 students aged 4 to 5 years, in a Primary School located in the South of State of Alagoas (Brazil), in order to verify the impact of these technologies in the process of student literacy. For this, a qualitative approach was used, with emphasis on participant observation as a data collection technique. As results, it was verified that the use of the DICTs had a positive impact on the performance, contributing to increase the engagement, motivation, attention, collaboration and sharing of student problem solving strategies.
\end{abstract}

\section{Introdução}

Nos últimos anos, tem-se observado um crescente interesse por parte da comunidade acadêmica e pesquisadores da área de Informática na Educação para o desenvolvimento, avaliação e uso das Tecnologias Digitais de Informação e Comunicação (TDIC) visando potencializar os processos de ensino e de aprendizagem de estudantes da Educação 
VII Congresso Brasileiro de Informática na Educação (CBIE 2018)

Anais do XXIV Workshop de Informática na Escola (WIE 2018)

Básica no cenário brasileiro [Silva et. al. 2015; Santos e Silva Junior 2016; dos Santos e de Santana 2018]. Além disso, as políticas públicas desenvolvidas pelo Ministério da Educação (MEC) e discutidas com a sociedade, comunidade acadêmica e científica têm contribuído para a inserção das TDIC no ambiente educacional [Inep 2015; Brasil 2017; Brasil 2018; Educação Conectada 2017].

$\mathrm{Na}$ Educação Básica, estudos recentes publicados na literatura nacional e internacional têm apresentados resultados de aprendizagem significativos da aplicação das TDICs como ferramentas de apoio no processo de ensino-aprendizagem nas etapas do Ensino Fundamental [de Santana et al. 2016; Vidotto et al. 2017] e no Ensino Médio [Santos et al. 2017(a); Santos et. al. 2017(b) de Adolfo, Machado e Warpechowski 2017] em domínios específicos do conhecimento. Entretanto, nota-se que a utilização das TDICs na prática docente na Educação Infantil ainda é um desafio no cenário brasileiro e requer novas investigações que abordem a seleção, aplicação e resultados de aprendizagem com o uso de ferramentas e recursos digitais em ambiente do mundo real [Bergamasco e Bergamasco 2013; Unesco 2017].

Neste contexto, as Diretrizes Curriculares Nacionais para Educação Infantil (DCNEI), primeira etapa da Educação Básica, estabelece que nas práticas pedagógicas devem ter como eixos norteadores as interações e a brincadeira e garantir experiências que possibilitem a utilização de gravadores, projetores, computadores, máquinas fotográficas e outros recursos tecnológicos e midiáticos [Brasil 2010]. Recentemente, com a homologação da Base Nacional Comum Curricular (BNCC) para a Educação Infantil e o Ensino Fundamental, foi definido para primeira etapa escolar seis direitos de aprendizagem e desenvolvimento, são eles: conviver, brincar, participar, explorar, expressar e conhecer-se. Dentre os direitos supracitados, vale destacar o direito de explorar, que de acordo com o documento, assegura na Educação Infantil, a condição de:

Explorar movimentos, gestos, sons, formas, texturas, cores, palavras, emoções, transformações, relacionamentos, histórias, objetos, elementos da natureza, na escola e fora dela, ampliando seus saberes sobre a cultura, em suas diversas modalidades: as artes, a escrita, a ciência e a tecnologia [Brasil 2018].

Diante disto, o presente trabalho relata a experiência do uso de TDIC na primeira etapa da Educação Básica. Com objetivo principal de verificar o impacto de diferentes tecnologias no processo de alfabetização dos estudantes na Educação Infantil. Para isso, foram utilizados dois softwares educacionais gratuitos: GCompris ${ }^{1}$ e Brincando com Ariê ${ }^{2}$, com um total $N=67$ estudantes com idade entre 4 e 5 anos e envolveu 4 professores de uma escola de Educação Básica, localizada ao Sul do estado de Alagoas. Tendo em vista a faixa etária dos estudantes e o ambiente natural investigado, optou-se por fazer uso do método de pesquisa qualitativo, com ênfase na observação participante como técnica de coleta de dados.

Os resultados principais obtidos ao longo deste estudo mostram que a utilização das TDIC aliadas aos processos de ensino e de aprendizagem impactou positivamente

\footnotetext{
${ }^{1}$ GCompris. Disponível em: http://gcompris.net/index-pt_BR.html

${ }^{2}$ Brincando com Ariê. Disponível em: http://brincandocomarie.com.br/
} 
VII Congresso Brasileiro de Informática na Educação (CBIE 2018)

Anais do XXIV Workshop de Informática na Escola (WIE 2018)

no desempenho, aumentou o engajamento, motivação e atenção dos estudantes no desenvolvimento das atividades com o uso das tecnologias no laboratório de informática. Além disso, melhorou a coordenação motora e desenvolveu habilidades de trabalho em equipe, colaborativo e compartilhamento de estratégias para resolver os desafios propostos através do computador. Esses resultados contribuem no desenvolvimento cognitivo dos estudantes, para adoção de TDIC na prática docente, elaboração de políticas públicas educacionais e novas ferramentas digitais com foco nos processos de ensino e de aprendizagem na primeira etapa da Educação Básica.

\section{Trabalhos Relacionados}

O crescente interesse de inserção da informática educativa pela comunidade acadêmica e científica visando aumentar a motivação e engajamento dos estudantes no processo de aprendizagem tem despertado a atenção de pesquisadores da área de Informática na Educação para o desenvolvimento de recursos digitais e modelos para auxiliar o professor na sala de aula [Reinoso et al. 2017; dos Santos 2018]. Neste sentido, Machado, Warpechowski e Vaz [2017] propuseram um Modelo de Interação entre Pares (MIP), que visa suprir a falta de recursos tecnológicos disponíveis na escola. Para validar o modelo, os mesmos pesquisadores realizaram um trabalho com objetivo de aplicar o MIP em uma turma com 15 alunos da Educação Infantil com idade entre 4 e 5 anos de uma escola pública localizada no Litoral Norte do Rio Grande do Sul.

Para isso, segundo [Machado, Warpechowski e Vaz 2017] buscou-se trabalhar com atividades alinhadas as que os alunos já haviam desempenhado ou que estavam sendo desenvolvidas em sala de aula. Diante disso, os pesquisadores abordaram, a priori, conceitos básicos de edição de textos e digitação para uma maior familiarização da criança com as letras do teclado de modo a contribuir para o processo de alfabetização. Em seguida, foi utilizado o software Aperta Letra ${ }^{3}$, uma ferramenta de edição de texto para crianças utilizarem com autonomia todos os recursos de formatação. Como resultados, os pesquisadores destacam que todos os estudantes interagiram com o software e exploraram suas funcionalidades. Além disso, o método foi eficaz no contexto da educação infantil, tendo em vista que as interações impactaram na aprendizagem dos estudantes com uso da tecnologia.

No trabalho de [Silva e Pires 2017] relata-se o uso de um jogo educacional, denominado "Eu sei Contar" como auxílio da matemática na Educação Infantil com crianças de 5 e 6 anos de idade, tendo como objetivo analisar o impacto causado pela utilização de ferramentas digitais gamificadas para aprendizagem infantil. Para isso, os pesquisadores realizaram um experimento, estruturado em quatro fases: (i) realização de diagnóstico com os alunos para identificar os interesses e o nível de familiaridade com tecnologia; (ii) aplicação de ludodiagnóse para identificar a familiaridade dos alunos com o conteúdo de matemática; (iii) apresentação do jogo educacional "Eu sei Contar" e coleta dos dados das atividades realizadas; e (iv) análise estatística dos dados. De acordo com os autores, o jogo "Eu sei Contar" é um software com interface simples, intuitiva e disponível na web com duas atividades: (i) contagem de elementos e (ii) contagem

\footnotetext{
${ }^{3}$ Software "Aperta Letra". Disponível em: http://apertaqual.org/

${ }^{4}$ Jogo "Eu sei contar". Disponível em: http://www.escolagames.com.br/
} 
VII Congresso Brasileiro de Informática na Educação (CBIE 2018)

Anais do XXIV Workshop de Informática na Escola (WIE 2018)

sequencial dos números naturais. Como resultados, notou-se uma melhora significativa de $30 \%$ no rendimento dos alunos após a aplicação do software em sala de aula.

Recentemente, [Silva, Filho e Filho 2017] realizaram um estudo com abordagem qualitativa de caráter interpretativo envolvendo 31 crianças de 5 anos de idade em um processo de produção de histórias com suporte digital, durante os anos de 2015 e 2016 em uma escola pública de Educação Infantil. Como objetivos, o presente estudo buscou acompanhar a produção textual com uso de um recurso digital na Educação Infantil e verificar se/como a utilização de um recurso digital favorece a produção de histórias na Educação Infantil. Para isso, as crianças utilizaram individualmente, tendo como suporte a mediação docente e o Objeto de Aprendizagem (OA) Histórias Fantásticas ${ }^{5}$, desenvolvido pelo Grupo de Pesquisa e Produção de Ambientes Interativos e Objetos de Aprendizagem (PROATIVA), da Universidade Federal do Ceará (UFC). Como resultados, os pesquisadores destacam que as crianças envolvidas no referido estudo demostraram grande facilidade de usar o computador e o OA Histórias Fantásticas.

Apesar dos relatos recentes de aplicação das TDICs na primeira etapa da Educação Básica [Machado, Warpechowski e Vaz 2017; Silva e Pires 2017; Silva, Filho e Filho], o uso efetivo da informática educativa no contexto da Educação Infantil ainda é um grande desafio no cenário brasileiro [Bergamasco e Bergamasco 2013], tanto pela falta de infraestrutura física e tecnológica inadequada, quanto pela necessidade de formação continuada dos docentes para exploração das TDIC integrada aos processos didático-pedagógicos [Figueiredo, Nobre e Passos 2015]. Diante disto, faz-se necessário realizar mais estudos que apresente resultados para apoiar o desenvolvimento e utilização das TDIC como ferramentas para auxiliar professores no processo de ensino e potencializar aprendizagem dos estudantes no processo de alfabetização.

\section{Materiais e Métodos}

O presente estudo foi realizado com 4 turmas, com um total de $N=67$ estudantes com idade entre 4 e 5 anos, envolvendo 4 professores da Educação Infantil e fazendo uso de dois softwares educacionais: GCompris e Brincando com Ariê, em uma escola de Educação Infantil, Ensino Fundamental e Médio, situada na região do Baixo do São Francisco, localizado ao Sul do Estado de Alagoas.

O software GCompris é uma suíte educacional livre de alta qualidade que inclui uma grande quantidade de atividades para crianças com idade entre 2 e 10 anos [GCompris 2018]. As atividades educativas estão organizadas em categorias, como: descoberta do computador, leitura, aritmética, ciências, geografia, jogos e outros. Cada atividade possui um número de estrelas que indica a faixa etária sugerida, por exemplo: 1, 2 ou 3 estrelas - para crianças entre 3 a 6 anos de idade, enquanto que, as atividades com 1, 2 ou 3 estrelas complexas - para crianças maiores de 7 anos de idade. Contudo, vale salientar que o software está em constante atualização e permite aos usuários de modo geral adaptar, fazer melhorias de acordo com as suas necessidades e compartilhar com a comunidade acadêmica.

A segunda ferramenta utilizada foi Brincando com Ariê, uma plataforma web gratuita composta por uma série de jogos educativos para auxiliar no processo de

\footnotetext{
${ }^{5}$ Histórias Fantásticas. Disponível em: http://www.proativa.vdl.ufc.br/oa/historias
} 
VII Congresso Brasileiro de Informática na Educação (CBIE 2018)

Anais do XXIV Workshop de Informática na Escola (WIE 2018)

alfabetização de estudantes da Educação Infantil. A plataforma visa estimular o aprendizado infantil através de atividades com foco na qualidade de design e usabilidade de jogos educativos [Brincando com Arie 2018]. Dentro do ambiente, o estudante pode visualizar todos os jogos ou selecionar as atividades educativas através das categorias: Brincando com Ariê, Português, Matemática e Idiomas.

Contudo, segundo [Gil 2012] para que o conhecimento possa ser considerado científico, torna-se necessário identificar operações mentais e técnicas que possibilitam a sua verificação. Diante disto, foi utilizada como método de pesquisa abordagem qualitativa com ênfase na observação participante como técnica de coleta de dados, tendo em vista a faixa etária dos estudantes e o ambiente natural investigado. Neste contexto [Creswell 2010] define a pesquisa qualitativa como um meio para explorar e entender o significado que os indivíduos ou grupos atribuem a um problema social ou humano. Segundo [Lüdke e André 2013] a observação permite a coleta de dados em situações em que é impossível outras formas de comunicação.

Para isso, foram executadas as seguintes etapas: (i) seleção das ferramentas; (ii) aplicação das ferramentas selecionadas em ambiente real; (iii) observação e coleta dos dados; e (iv) análise dos resultados e discussão. Na primeira etapa, buscou-se selecionar tecnologias educacionais para auxiliar no processo de alfabetização de estudantes da Educação Infantil, com base na faixa etária entre 3 e 5 anos de idade. Como resultado, foram escolhidos: GCompris e Brincando com Airê, ambos gratuitos e disponíveis na web. Na segunda etapa, foram executadas atividades disponíveis nos softwares educativos, conforme mostrado na Tabela 1.

Tabela 1 - Softwares e atividades educacionais realizadas.

\begin{tabular}{|c|c|c|c|}
\hline Softwares & Atividades & Breve descrição & Objetivos \\
\hline \multirow{3}{*}{ 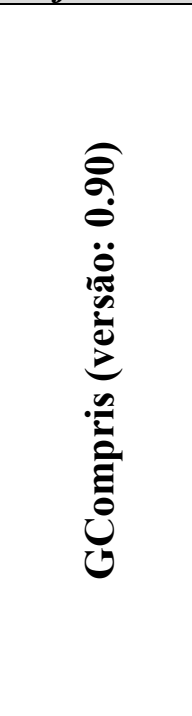 } & $\begin{array}{l}\text { Mova o mouse } \\
\text { ou toque a tela }\end{array}$ & $\begin{array}{l}\text { O estudante precisa mover o mouse sobre } \\
\text { uma área formada com pequenos blocos e } \\
\text { descobrir fotos de animais silvestres de } \\
\text { domésticos ao fundo. }\end{array}$ & \multirow{3}{*}{ 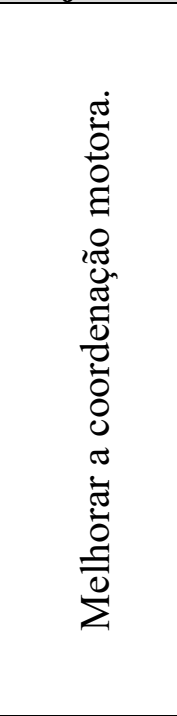 } \\
\hline & $\begin{array}{l}\text { Clique ou } \\
\text { toque }\end{array}$ & $\begin{array}{l}\text { O estudante deve clicar para excluir os } \\
\text { blocos e descobrir os animais silvestres e } \\
\text { domésticos ao fundo. }\end{array}$ & \\
\hline & $\begin{array}{l}\text { Clique e } \\
\text { desenhe }\end{array}$ & $\begin{array}{l}\text { Esta atividade permite que o estudante } \\
\text { desenhe uma figura clicando em cada } \\
\text { ponto na cor azul, na sequência. Cada vez } \\
\text { que um ponto é selecionado o próximo } \\
\text { ponto azul aparece até formar o desenho. }\end{array}$ & \\
\hline 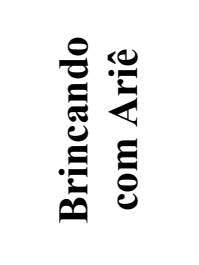 & $\begin{array}{l}\text { Yuki no } \\
\text { Caminho das } \\
\text { Letras }\end{array}$ & $\begin{array}{l}\text { Neste jogo, o Yuki quer encontrar a } \\
\text { gatinha Luna, mas para isso o estudante } \\
\text { precisa completar as palavras com as letras } \\
\text { que faltam. O jogo apresenta três níveis de } \\
\text { dificuldades: fácil, médio e difícil. }\end{array}$ & 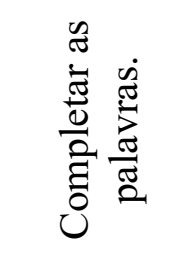 \\
\hline
\end{tabular}


VII Congresso Brasileiro de Informática na Educação (CBIE 2018)

Anais do XXIV Workshop de Informática na Escola (WIE 2018)

\begin{tabular}{l|l|l|l}
\hline & $\begin{array}{l}\text { O estudante precisa formar as palavras. } \\
\text { Para isso, ele deve clicar na porção mágica } \\
\text { para liberar as maçãs enfeitiçadas pelos os } \\
\text { vilões. E quando as maçãs voltarem ao } \\
\text { normal, basta clicar sobre as mesmas para } \\
\text { o gatinho Yuki colocar todas elas em } \\
\text { ordem e formar as palavras. }\end{array}$ \\
$\begin{array}{lll}\text { Yuki e os } \\
\text { Vilões }\end{array}$
\end{tabular}

As atividades foram executadas no período de março a abril de 2018. Os estudantes tiveram uma hora de aula por semana no laboratório de informática com a presença das professoras. Nas três primeiras aulas, foi executado o software GCompris e os estudantes realizaram as atividades "Mova o mouse ou toque a tela", "Clique ou toque" e "Clique e desenhe", respectivamente, visando melhorar a coordenação motora. $\mathrm{Na}$ quarta aula, acessamos a plataforma "Brincando com Ariê" e foi proposto o jogo educativo "Yuki no Caminho das Letras" com objetivo de completar as palavras. Por último, na quinta aula, foi utilizado o jogo "Yuki e os Vilões" com objetivo de formar as palavras.

Durante esse período, foram feitas anotações em um diário de bordo do pesquisador com as observações in loco, fotos, informações descritivas, as falas e comportamentos dos estudantes com o uso das TDIC no laboratório de informática com o suporte docente para auxiliar no processo de desenvolvimento cognitivo. De acordo com [Lüdke e André 2013] essas medidas têm um caráter meramente prático, no sentido de ajudar a organização e análise dos dados. Na próxima seção, apresentamos os principais resultados e discussão.

\section{Resultados e Discussão}

A priori, na primeira semana de execução dessas atividades com o uso do computador no laboratório de informática, observou-se que, um percentual pequeno dos estudantes apresentou dificuldade relacionada à coordenação motora para manusear o mouse e precisou do apoio da professora para auxiliar durante a realização das atividades. Entretanto, mesmo estes estudantes, em pouco tempo os foram adquirindo familiaridade com o computador e obtendo segurança no controle do mouse, confirmando os resultados do estudo de [Cole e de Souza 2017].

A partir da segunda semana de estudos, notou-se uma maior interação dos estudantes com o uso das TDICs, realização das atividades em menos tempo e de acordo com os professores, percebeu-se uma felicidade visível no rosto e o brilho no olhar das crianças ao completar cada tarefa. Além disso, observou-se também que os estudantes com melhor habilidade no domínio do mouse, ao concluir sua tarefa auxiliava o colega mais próximo (sentado ao lado) com dicas de como fazer mais rápido para avançar de fase. Em determinado momento, um aluno falou para o colega ao lado: "ei, segure o mouse com os dois dedos aqui, nesses botões e depois aperte esse!", desenvolvendo assim o trabalho em equipe, colaborativo e o compartilhamento de estratégias para completar as atividades. Estes achados são semelhantes aos de [Machado, Warpechowski e Vaz 2017] e reforçam que a utilização adequada das TDIC alinhada aos processos de ensino e de aprendizagem pode potencializar o desenvolvimento dos 
VII Congresso Brasileiro de Informática na Educação (CBIE 2018)

Anais do XXIV Workshop de Informática na Escola (WIE 2018)

estudantes nesta primeira etapa escolar, além disso, desenvolve características e habilidades importantes do século XXI.

As atividades propostas nas três primeiras semanas contribuíram positivamente para melhorar a coordenação motora dos estudantes, na familiarização com ambiente tecnológico e na descoberta de novos animais silvestres e domésticos, gerando assim, diálogos entre os estudantes e as professoras a respeito da vida e convívio desses animais em seu hábitat natural, criando assim, de acordo com [Valente 1998] condições de aprendizagem, onde o professor passa a ser criador de ambientes de aprendizagem e o facilitador do processo de desenvolvimento intelectual do aluno. Isso foi importante, pois preparou os estudantes para realizar as próximas atividades com os objetivos de completar e formar as palavras através de jogos educacionais.

Segundo [Valente 1998] os jogos, do ponto de vista da criança, constituem a maneira mais divertida de aprender. De fato, isso foi percebido através dos jogos educacionais "Yuki no Caminho das Letras" e "Yuki e os Vilões" disponíveis na plataforma web Brincando com Ariê. No primeiro jogo, os estudantes de 4 e 5 anos se divertiram e aprenderam explorando os três níveis do jogo: fácil, médio e difícil. Com o objetivo de completar as palavras, no nível fácil, todos os estudantes completaram com apenas uma letra as palavras de objetos simples, como por exemplo: sol, bola, pipa, e etc. Já no nível médio, completaram com duas letras, palavras de objetos como: lupa, gato, raio, e etc. Enquanto que no nível difícil, os estudantes foram desafiados a formar o nome completo dos objetos, como por exemplo: flor, casa, coco, e etc. Em cada nível, ao completar uma palavra, o estudante foi recompensado com uma estrela no jogo e avançou de fase. Na Figura 1, apresentamos os três níveis do jogo.

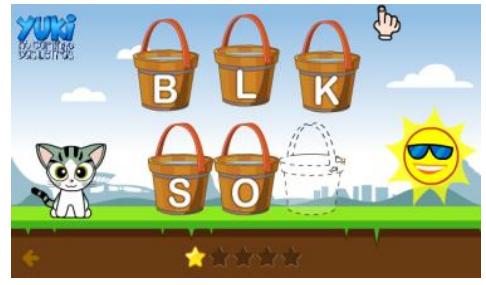

Fácil

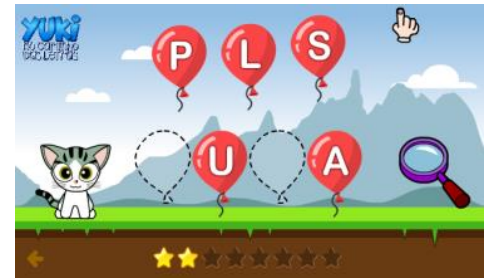

Médio

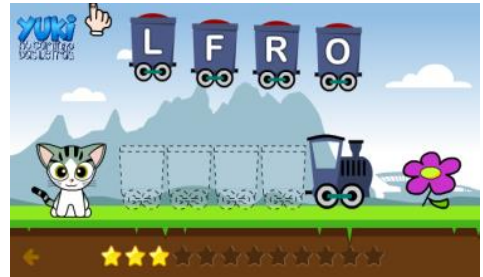

Difícil

Figura 1. Apresentação dos três níveis do jogo educacional "Yuki no Caminho das Letras".

Contudo, vale destacar alguns comentários durante a realização das atividades no laboratório de informática. Um estudante que estava no nível fácil, falou: "isso é muito legal! Muito bom mesmo, gostei tia". Isso despertou o interesse de outros estudantes que em seguida perguntaram para professora: "tia, como faço para jogar na minha casa?", "tia, anote na minha agenda para minha mãe ver", "tia, eu quero também”, "tia, eu consegui passar para outra fase". Durante esse período, a professora sempre interagiu e auxiliou os estudantes que apresentaram alguma dificuldade no processo de formação das palavras. Em outro momento, uma criança de 5 anos falou: "tia, falta pouco para terminar o nível difícil, ele é muito fácil!".

Por último, os estudantes exploram o jogo "Yuki contra os Vilões" que oferece apenas dois níveis: fácil e difícil. Neste jogo, os estudantes formaram palavras de objetos já conhecidos em sala de aula, como por exemplo: raio, mação, balão, etc. Nesta etapa, um estudante disse: "tia, eu fiz a palavra gato", em seguida, espontaneamente a 
VII Congresso Brasileiro de Informática na Educação (CBIE 2018)

Anais do XXIV Workshop de Informática na Escola (WIE 2018)

criança soletrou a palavra em voz alta para a professora e colegas na sala ouvirem, e a professora, respondeu: “muito bem, parabéns!”. Logo, chamou atenção dos colegas que também repetiram outras palavras à medida que completavam. Alguns estudantes, ao completar todas as fases no jogo pediram para professora: "tia, quero fazer de novo. Quero mais! Posso repetir tia?”.

Em vários momentos, houve intervenção das professoras para ajudar os estudantes com maior dificuldade em formar as palavras utilizando como estratégias o som das silabas. Diante disso, notou-se engajamento, motivação e atenção dos estudantes para formar corretamente as palavras propostas pelo jogo educacional. Esses resultados estão de acordo com os apontados por [Levay et al. 2015], além disso, constatou-se um impacto positivo no desenvolvimento das atividades como relatados por [Silva e Pires 2017] e contribuiu, de acordo com [Corbellini, Real e Michailoff 2015] para atuação ativa dos estudantes no processo de ensino e aprendizagem mediada pelas TDIC no contexto da Educação Infantil.

\section{Considerações Finais}

O presente estudo relatou o uso das TDIC com foco no processo de alfabetização de estudantes e envolveu quatro professoras da Educação Infantil. Com os resultados obtidos, destacaram que após a realização das atividades "Mova o mouse ou toque a tela", "Clique ou toque" e "Clique e desenhe" através do software educacional GCompris, melhorou a coordenação motora das crianças de 4 e 5 anos de idade. Além disso, executar essas tarefas despertou a atenção e ampliou os diálogos entre os estudantes e docentes a respeito dos animais silvestres, domésticos e seu hábitat natural.

Por último, o uso dos jogos educacionais "Yuki no Caminho das Letras" e "Yuki e os Vilões" por meio da plataforma web Brincando com Ariê, contribuiu no processo alfabetização dos estudantes ao realizar atividades de modo divertidas através do computador tendo como objetivos completar e formar as palavras. Diante disto, os resultados permitem concluir que a seleção, planejamento e uso adequado das TDIC alinhadas aos processos de ensino-aprendizagem impactou significativamente no desempenho de aprendizagem dos estudantes, na motivação, engajamento, foco na resolução das atividades com o suporte docente e ampliou as interações didáticopedagógicas no contexto da Educação Infantil.

Como trabalhos futuros, pretende-se contribuir no desenvolvimento de novos recursos digitais, aplicação no cenário educacional e avaliações empíricas aprofundadas, visando identificar como a experiencia do uso desses softwares influenciou em aspectos psicológicos ligados ao processo de ensino e aprendizagem das crianças, como motivação, engajamento e experiencia de fluxo [Santos et. al. 2018], em busca de enriquecer a comunidade de Informática na Educação e disseminar práticas pedagógicas inovadoras com o uso das TDIC para potencializar os processos de ensino e de aprendizagem de docentes e estudantes da Educação Básica no Brasil.

\section{Referências}

Bergamasco, E. C., \& Bergamasco, L. C. C. (2013). A utilização das Tecnologias de Informação e Comunicação na Educação Infantil: avanços e desafios. In Anais do Workshop de Informática na Escola (Vol. 1, No. 1, p. 329). 
VII Congresso Brasileiro de Informática na Educação (CBIE 2018)

Anais do XXIV Workshop de Informática na Escola (WIE 2018)

Brasil, Ministério da Educação. (2018). Base Nacional Comum Curricular. Disponível em: http://basenacionalcomum.mec.gov.br/abase/

Brasil, Ministério da Educação. Secretaria de Educação Básica. (2010). Diretrizes Curriculares Nacionais para a Educação Infantil. Brasília: MEC/SEB.

Brasil, Presidência da República. (2017). Decreto nº 9.099, de 18 de julho de 2017.

Brincando com Ariê. (2018). Disponível em: http://brincandocomarie.com.br/

Cole, K., \& de Souza, M. A. S. (2017). Iniciação Digital na Educação Infantil: aprendendo o alfabeto com o uso do computador. Revista de Pesquisa Interdisciplinar, 1(Esp).

Creswell, John W. (2010). Projeto de Pesquisa: métodos qualitativo, quantitativo e misto. $3^{\mathrm{a}}$ ed. - Porto Alegre: Artmed.

da Silva Adolfo, M., Machado, D., \& Warpechowski, M. (2017). Ensino e Aprendizagem de Biologia no Ensino Médio através da Informática Educativa. In Anais do Workshop de Informática na Escola (Vol. 23, No. 1, p. 608).

da Silva, M. A., Macedo Filho, J. A., \& de Castro Filho, J. A. (2017). Histórias Fantásticas: produção de textos com suporte digital na Educação Infantil. In Anais do Workshop de Informática na Escola (Vol. 23, No. 1, p. 1060).

de Santana, S. J., Paiva, R., Bittencourt, I. I., Ospina, P. E., de Amorim Silva, R., \& Isotani, S. (2016). Evaluating the impact of Mars and Venus Effect on the use of an Adaptive Learning Technology for Portuguese and Mathematics. In Advanced Learning Technologies (ICALT), 2016 IEEE 16th International Conference on (pp. 31-35). IEEE.

dos Santos, W. O. (2018). EGV: A Methodology Proposal to Educational Games Virtualization. RENOTE, 16(1).

dos Santos, W. O., \& de Santana, S. J. (2018). Os Jogos Digitais São Realmente Melhores que os Jogos Tradicionais para Ensinar Matemática? Uma Análise sob a Concentração dos Estudantes. RENOTE, 16(1).

dos Santos, W. O., Bittencourt, I. I., Isotani, S., Dermeval, D., Marques, L. B., \& Silveira, I. F. (2018). Flow Theory to Promote Learning in Educational Systems: Is it Really Relevant?. Brazilian Journal of Computers in Education, 26(02), 29.

Educação Conectada, Brasil. Ministério da Educação. (2017). Portaria n ${ }^{\circ} 1.602$, de 28 de dezembro de 2017.

Figueiredo, G., Nobre, I., \& Passos, M. L. S. (2015). Tecnologias computacionais na educação: Desafios na prática docente. In Anais do Workshop de Informática na Escola (Vol. 21, No. 1, p. 127).

GCompris. (2018). Disponível em: http://gcompris.net/index-pt_BR.html

Gil, Antonio Carlos. (2012). Métodos e técnicas de pesquisa social. $6^{\text {a }}$ ed. - São Paulo: Atlas.

Inep, M. (2015). Plano Nacional de Educação PNE 2014-2024: Linha de base. Brasília: INEP. 
VII Congresso Brasileiro de Informática na Educação (CBIE 2018)

Anais do XXIV Workshop de Informática na Escola (WIE 2018)

Levay, P., Falcão, T. P., Diniz, J., \& de Souza, R. (2015). Uma Experiência de Uso de Jogos Digitais como Ferramentas de Apoio para Aprendizagem de Inglês por Crianças. In Anais do Workshop de Informática na Escola (Vol. 21, No. 1, p. 207).

Lüdke, Menga; André, Marli E. D. A. (2013). Pesquisa em educação: abordagens qualitativas. $2^{\text {a }}$ ed. - Rio de Janeiro: E.P.U.

Machado, D., Warpechowski, M., \& Vaz, D. (2017). Modelo de Interação Entre Pares (MIP): viabilizando o ensino da informática educativa na Educação Infantil. In Anais do Workshop de Informática na Escola (Vol. 23, No. 1, p. 353).

Real, L. C., Corbellini, S., \& Michailoff, F. (2015). Jogos online: ferramentas nas Intervenções Psicopedagógicas. In Anais do Workshop de Informática na Escola (Vol. 21, No. 1, p. 147).

Reinoso, L., Amorim, M., Tavares, O., \& Almeida, R. (2017). Framework CAP 1.0 para criação e uso de arquiteturas pedagógicas. In Brazilian Symposium on Computers in Education (Simpósio Brasileiro de Informática na Educação-SBIE) (Vol. 28, No. 1, p. 384).

Santos, E., Oliveira, F., Gomes, A. S., \& Toscano, J. (2017). Mapeamento sistemático acerca das práticas docentes com o uso de Recursos Educacionais Abertos. In Brazilian Symposium on Computers in Education (Simpósio Brasileiro de Informática na Educação-SBIE) (Vol. 28, No. 1, p. 263).

Santos, W. O., \& da Silva Junior, C. G. (2016). Virtualização de Jogos Educativos: Uma Experiência no Ensino de Matemática. Revista Brasileira de Informática na Educação.

Santos, W. O., Rosalino, G., \& Silva, C. (2017). Desafios das Diagonais: Um Jogo Casual para o Aprimoramento do Raciocínio Lógico. In Anais dos Workshops do Congresso Brasileiro de Informática na Educação (Vol. 6, No. 1, p. 168).

Silva, E., \& de Sousa Pires, F. G. (2017). O uso do jogo educacional Eu sei Contar como auxílio da matemática no ensino infantil. In Anais do Workshop de Informática na Escola (Vol. 23, No. 1, p. 520).

Silva, S. F., Ferreira, A., Souza, A. A., Galdino, E., Oliveira, M. L. S., Neto, S., \& Oliveira, W. (2015). Relato de Experiência de Ensino de Computação no Ensino Fundamental em Estágio Supervisionado da Universidade de Pernambuco no Campus Garanhuns. In $23^{\circ}$ Workshop sobre Educação em Computação (pp. 1-10).

Unesco, Organização das Nações Unidas para a Educação, a Ciência e a Cultura. (2017). TIC, educação e desenvolvimento social na América Latina e o Caribe. Montevidéu, Uruguai.

Valente, José Armando. (1998). Computadores e conhecimento: repensando a educação. 2. ed. - Campinas, SP: UNICAMP/NIED.

Vidotto, K. N. S., Lopes, L., Pozzebon, E., \& Frigo, L. (2017). Ambiente Inteligente de Aprendizagem MAZK com alunos do Ensino Fundamental II na disciplina de Ciências. In Brazilian Symposium on Computers in Education (Simpósio Brasileiro de Informática na Educação-SBIE) (Vol. 28, No. 1, p. 1367). 